\title{
Intensive care use and mortality among patients with ST elevation myocardial infarction: retrospective cohort study
} Andrew M Ryan, ${ }^{2,5}$ Robert W Yeh,, 8 Brahmajee K Nallamothu $2,4,5,10$

For numbered affiliations see end of the article. Correspondence to: TValley valleyt@umich.edu or @tsvalley on Twitter (ORCID 0000-0002-5766-4970) Additional material is published online only. To view please visit the journal online.

Cite this as: BMJ 2019;365:11927 http://dx.doi.org/10.1136/bmj.l1927

Accepted: 16 April 2019

\section{ABSTRACT}

OBJECTIVE

To evaluate the effect of intensive care unit (ICU) admission on mortality among patients with ST elevation myocardial infarction (STEMI).

\section{DESIGN}

Retrospective cohort study.

\section{SETTING}

1727 acute care hospitals in the United States.

\section{PARTICIPANTS}

Medicare beneficiaries (aged 65 years or older) admitted with STEMI to either an ICU or a non-ICU unit (general/telemetry ward or intermediate care) between January 2014 and October 2015.

MAIN OUTCOME MEASURE

30 day mortality. An instrumental variable analysis was done to account for confounding, using as an instrument the additional distance that a patient with STEMI would need to travel beyond the closest hospital to arrive at a hospital in the top quarter of ICU admission rates for STEMI.

RESULTS

The analysis included 109375 patients admitted to hospital with STEMI. Hospitals in the top quarter of ICU admission rates admitted $85 \%$ or more of STEMI patients to an ICU. Among patients who received ICU care dependent on their proximity to a hospital in the top quarter of ICU admission rates, ICU admission was associated with lower 30 day mortality than non-ICU admission (absolute decrease 6.1 (95\% confidence interval -11.9 to -0.3 ) percentage points). In a separate analysis among patients with non-STEMI, a group for whom evidence suggests that routine ICU care does not improve outcomes, ICU admission was not associated with differences in mortality (absolute increase 1.3 ( -0.9 to 3.4 ) percentage points).

\section{WHAT IS ALREADY KNOWN ON THIS TOPIC}

On average, $75 \%$ of patients with ST elevation myocardial infarction (STEMI) in the US are admitted to an intensive or coronary care unit (ICU)

Most patients with STEMI receive definitive reperfusion treatment before ICU admission

Whether ICU admission is beneficial for STEMI patients in contemporary practice is unknown

\section{WHAT THIS STUDY ADDS}

This study suggests that ICU admission improves mortality for STEMI patients who could be treated in an ICU or non-ICU unit

STEMI patients who might benefit from ICU care should be identified, and the effect of expanded ICU access for these patients should be tested

\section{CONCLUSIONS}

ICU care for STEMI is associated with improved mortality among patients who could be treated in an ICU or non-ICU unit. An urgent need exists to identify which patients with STEMI benefit from ICU admission and what about ICU care is beneficial.

\section{Introduction}

Survival after ST elevation myocardial infarction (STEMI) has increased by nearly $20 \%$ over the past two decades. ${ }^{1}$ Complications from STEMI, such as cardiogenic shock or life threatening arrhythmias, have also fallen markedly. ${ }^{2}$ This improvement is usually attributed to the accessibility and implementation of early reperfusion therapy, which typically occurs before patients are admitted to an intensive or coronary care unit (ICU). Nevertheless, 75\% of patients with STEMI in the US are admitted to an ICU. ${ }^{3}$ The costs of this practice are enormous. ICU admissions are on average 2.5 times more costly than non-ICU admissions, and critical care services now account for almost $1 \%$ of the US gross domestic product. ${ }^{4}$

Whether ICU care for patients with STEMI provides a benefit over lower levels of care, such as general, telemetry, or intermediate care, is poorly understood. ${ }^{5}$ Guidelines for STEMI care also provide conflicting advice. Recent European guidelines recommended admitting all patients with STEMI to an ICU. ${ }^{6}$ Previous American guidelines suggested that STEMI patients at low risk may not need ICU level care, ${ }^{7}$ but recent guideline updates did not specifically discuss the role of ICU care for STEMI. ${ }^{1}$ This uncertainty is reflected in practice. Wide variation exists among hospitals in the use of ICUs for STEMI, both in the US and worldwide. ${ }^{38}$

In this context, we sought to evaluate the effect of ICU admission on mortality for patients with STEMI in the US. As the decision to use an ICU is inherently linked to a patient's severity of illness, previous observational studies were limited by confounding by indication. ${ }^{9}$ To overcome this, we used an instrumental variable analysis to examine the effect of ICU admission on patients with borderline or discretionary ICU needs (that is, those patients who could reasonably receive care in an ICU or non-ICU unit). As mortality after STEMI is declining owing to broader use of reperfusion therapy, ${ }^{10}$ we hypothesized that ICU admission would not be associated with a mortality benefit.

\section{Methods}

Study cohort

We did a retrospective cohort study of all fee-forservice Medicare beneficiaries aged 65 years and older who were admitted to a hospital in the US for 
STEMI between January 2014 and October 2015. We identified patients with STEMI by using international classification of diseases, ninth revision, clinical modification (ICD-9-CM) primary diagnosis codes for STEMI (supplementary table A). ${ }^{10}$ We excluded patients with STEMI admitted to hospitals without ICU capabilities or admitted directly (that is, transferred in) from other acute care hospitals. We also excluded patients for whom data necessary for analyses were missing (such as ZIP codes $(\mathrm{n}=1415)$, hospital characteristics $(n=805)$, or hospital identifiers $(n=2))$ (supplementary figure A).

\section{Data source}

We linked inpatient claims from the Medicare Provider Analysis and Review File to mortality data in the Medicare Beneficiary Summary File. ${ }^{11}$ Characteristics of hospitals came from the American Hospital Association's Annual Surveys and the Healthcare Cost Reporting Information Systems. ${ }^{12} 13$ We obtained population and geographic information by linking the patient's ZIP code of residence to 2010 US census data.

\section{Patient and public involvement}

Patients were not involved in the development of the research question, study design, or outcome measures. Patients were not involved in the recruitment, conduct, or interpretation of the study. There are no specific plans to disseminate the results of the research to study participants or to relevant patients beyond the usual channels of publication.

\section{Exposure variable, outcome variable, and covariate} definitions

We used room and board charges for each Medicare beneficiary to establish the level of care for which the patient was billed. Thus, we relied on the US Centers for Medicare and Medicaid Services' definition of an ICU, which is based on two criteria. ${ }^{14}$ Firstly, an ICU must have lifesaving equipment available for immediate use and be geographically and identifiably separate from general routine care areas. Secondly, a single nurse must take care of no more than two patients, and nursing staff cannot be shared between an ICU and other units that provide lower levels of care.

The exposure variable was admission to ICU (the presence of an ICU or coronary care unit (CCU) revenue center code in the administrative billing record). ${ }^{15}$ We defined non-ICU admission as any admission to a general/telemetry (the lack of any ICU or CCU revenue center code) or intermediate care ward (the presence of an intermediate ICU or intermediate CCU revenue center code). ${ }^{16}$ The primary study outcome was 30 day all cause mortality, measured from the time of hospital admission.

To account for differences between patients admitted toICU or non-ICU units, weused patients' characteristics such as age, sex, race/ethnicity, comorbid illness, ${ }^{17}$ severity of illness, cardiac procedures performed during the hospital admission, median household income, and urbanicity for adjustment. We captured severity of illness through secondary ICD-9-CM diagnosis and procedural codes for acute organ dysfunction or mechanical ventilation (supplementary table A). ${ }^{18} 19$ We identified percutaneous coronary intervention, coronary artery bypass graft procedure, and thrombolytics by using ICD-9-CM procedural codes. ${ }^{2021}$ Median household income was based on the patient's ZIP code of residence, using 2010 US census data. Urbanicity was defined by the National Center for Health Statistics Urban-Rural Classification Scheme. ${ }^{22}$ We also used characteristics of hospitals, including geographic region, teaching hospital status by resident to hospital bed ratio, hospital size by number of beds, ICU size by proportion of total hospital beds, proportion of Medicaid patients among all admitted patients, nursing ratio (nursing full time equivalents per 1000 patient days averaged over the entire hospital), and annual hospital STEMI case volume, for adjustment.

\section{Instrumental variable analysis}

Because admission to an ICU is likely to be correlated with severity of illness (that is, sicker patients are admitted to an ICU and are also more likely to die) and observational data often lack all variables needed for adjustment, standard multivariable regression is likely to be biased through confounding by indication. ${ }^{9}$ We found that a multivariable adjusted model yielded biased estimates relative to those from an instrumental variable model using the Wooldridge's score test of endogeneity $\left(\mathrm{F}_{1,1726}=5.1 ; \mathrm{P}=0.02\right) .{ }^{23}$ Therefore, we used an instrumental variable analysis to account for confounding.

In an instrumental variable analysis, an instrument is used to adjust a patient's likelihood of receiving the treatment. In this study, we used differential distance as the instrument. It has been used previously in myocardial infarction by McClellan and colleagues to examine the effect of cardiac catheterization on mortality. ${ }^{24}$ Conceptually, distance to a hospital acts as an instrument because, in general, most people choose their residence for reasons unrelated to nearby hospitals. However, when a person has a STEMI or other acute illness, they are likely to be taken to the nearest hospital.

Differential distance represents the additional distance that a patient would need to travel, beyond the closest hospital, to arrive at a hospital in the top quarter of ICU admission rates for STEMI. We calculated differential distance as the difference between the distance from a patient's residence to the nearest high ICU use hospital (that is, a hospital in the top quarter of ICU admission rates for STEMI) and the distance from a patient's residence to the nearest hospital of any type. Distances were measured by using the linear arc distance function, which calculates the distance between the geographic coordinates of the hospital and the centroid of the patient's residential ZIP code. The median differential distance to a high ICU use hospital was 6.8 miles.

To show its validity, an instrument must meet two conditions. ${ }^{25}$ Firstly, the instrument must be associated 
with the treatment. Secondly, the instrument should have no relation with the outcome, except through the treatment. As an example, in a randomized trial, the randomization tool may act as the perfect instrument, increasing or decreasing the probability that a person receives a given treatment while also being otherwise unrelated to the study outcome.

In this study, we showed the strength of the instrument in three ways. Firstly, differential distance was highly correlated with ICU admission (partial $\left.\mathrm{F}_{1,1726}=64 ; \mathrm{P}<0.001\right)$. An $\mathrm{F}$ statistic greater than 10 generally indicates that an instrument is strongly associated with the treatment. ${ }^{25}$ Secondly, for every 10 mile increase in differential distance, the probability of ICU admission decreased by $1.8 \%$. Thirdly, more patients who lived close to a high ICU use hospital were admitted to an ICU than patients who lived far from a high ICU use hospital: 73.8\% (40 354/54691 patients) who lived less than the median (6.8 miles) were admitted to an ICU compared with $63.8 \%$ (34873/54684 patients) whose differential distance was more than 6.8 miles (table 1 ).

No empiric method exists to show that the instrument is not associated with the outcome other than through the treatment. ${ }^{25}$ The recommended way of evaluating this condition is to stratify observed characteristics by the instrument and then carefully examine balance. ${ }^{2527}$ Balance of observed characteristics across the instrument provides confidence that unobserved characteristics are similarly balanced. We examined whether patients' characteristics were balanced across the distribution of theinstrument by using standardized differences (table 1). Generally, standardized differences less than 0.1 indicate balance, ${ }^{26}$ and we showed reasonable balance between the two groups, except for race/ethnicity and urbanicity. Imbalances in race/ethnicity and urbanicity are recognized to be inherent to the use of distance instruments ${ }^{27}$

\section{Interpretation of instrumental variable results}

The results of a standard regression represent the treatment effect for the average patient. The results of an instrumental variable analysis represent the treatment effect for the statistically marginal patient. ${ }^{28}$ Marginal patients represent those whose likelihood of receiving the treatment depended on the instrument. A patient in a randomized trial might only receive an experimental treatment if randomized to it, and a marginal patient in this study received ICU care only because they lived close to a hospital with a high ICU admission rate for STEMI. Thus, statistically marginal patients might be considered clinically to have borderline or discretionary ICU needs-they might receive care in an ICU or outside of an ICU depending on the hospital to which they are admitted because different providers might reasonably disagree about the best location for the patient's care.

Marginal patients cannot be identified within an instrumental variable analysis. ${ }^{28}$ However, we estimated the size of the marginal population of patients and their population level characteristics by using the method of Angrist and Pischke. ${ }^{29}$ The statistical code for these estimates is given in the supplementary methods.

\section{Statistical analysis}

To account for characteristics of patients and hospitals, we used multivariable logistic regression models. In the instrumental variable analysis, we used two stage least squares regression with adjustment for the same patient and hospital characteristics. To overcome the imbalances in race/ethnicity and urbanicity when using a distance instrument, we specifically included these characteristics in all adjusted models, including the instrumental variable analysis. ${ }^{27}$ We used predictive margins to estimate adjusted absolute differences in outcomes. All models estimated robust standard errors with clustering at the hospital level.

\section{Subgroup, sensitivity, and falsification analyses}

To test whether the results were consistent for specific target populations, to assess for effect measure modification, and to examine mechanisms for identified differences, we did several subgroup, sensitivity, and falsification analyses. Firstly, to evaluate whether severely ill patients could be driving the association between ICU admission and mortality, instrumental variable analyses were stratified by organ failure score and also repeated after exclusion of patients with ICD-9-CM diagnosis or procedural codes for respiratory failure or shock. Secondly, given the imbalance in race/ethnicity and urbanicity when using a distance instrument, we did separate subgroup analyses with these characteristics.

Thirdly, to examine whether patients with life limiting treatment preferences could influence the results, we did separate instrumental variable analyses stratified by whether or not patients were aged 80 years or older, excluding patients who received a billing code for palliative care, ${ }^{30}$ or excluding patients who did not receive percutaneous coronary intervention, coronary artery bypass graft, or thrombolytics. To ensure that differences in outcomes based on age were not missed by dichotomizing a continuous variable, we did a non-linear two stage residual inclusion instrumental variable analysis and then used predictive margins to estimate adjusted absolute differences in 30 day mortality at 5 year age intervals.

Fourthly, to assess whether particular hospital capabilities could be influencing the results, we did separate subgroup analyses excluding hospitals without percutaneous coronary intervention capabilities or intermediate care. Fifthly, to assess the consistency of the results to the modeling method, we repeated the instrumental variable analysis using a non-linear two stage residual inclusion model. ${ }^{31}$ Confidence intervals for the two stage residual inclusion model were based on 3000 non-parametric bootstrap samples with replacement. Finally, as a falsification test, we repeated the instrumental variable analysis for non-STEMI patients, a group for which increasing data suggest that routine ICU care does not improve outcomes. ${ }^{32}$ 


\begin{tabular}{|c|c|c|c|}
\hline \multirow[b]{2}{*}{ Characteristics } & \multicolumn{2}{|c|}{ Differential distancet } & \multirow{2}{*}{$\begin{array}{l}\text { Standardized } \\
\text { difference } \neq\end{array}$} \\
\hline & $<6.8$ miles & $\geq 6.8$ miles & \\
\hline Patients & $54691(50.0)$ & $54684(50.0)$ & \\
\hline ICU admission & $40354(73.8)$ & $34873(63.8)$ & 0.22 \\
\hline Intermediate care admission & $8330(15.2)$ & $12610(23.1)$ & 0.20 \\
\hline Mean (SD) age, years & $76.1(7.9)$ & $76.0(7.9)$ & 0.01 \\
\hline \multicolumn{3}{|l|}{ Age group, years: } & \multirow[t]{4}{*}{0.01} \\
\hline $65-74$ & $26857(49.1)$ & $27129(49.6)$ & \\
\hline $75-84$ & $17519(32.0)$ & $17471(32.0)$ & \\
\hline$\geq 85$ & $10315(18.9)$ & $10084(18.4)$ & \\
\hline \multicolumn{3}{|l|}{ Sex: } & \multirow[t]{3}{*}{0.03} \\
\hline Male & $31686(57.9)$ & $32358(59.2)$ & \\
\hline Female & $23005(42.1)$ & $22326(40.8)$ & \\
\hline \multicolumn{3}{|l|}{ Race/ethnicity: } & \multirow[t]{4}{*}{0.16} \\
\hline White & $46105(84.3)$ & $48960(89.5)$ & \\
\hline Black & $4650(8.5)$ & $2897(5.3)$ & \\
\hline Other & $3936(7.2)$ & $2827(5.2)$ & \\
\hline \multicolumn{3}{|l|}{ Urbanicity: } & \multirow[t]{7}{*}{0.41} \\
\hline Large central metropolitan & $16659(30.5)$ & $8594(15.7)$ & \\
\hline Large suburban metropolitan & $12741(23.3)$ & $12235(22.4)$ & \\
\hline Medium metropolitan & $11316(20.7)$ & $12938(23.7)$ & \\
\hline Small metropolitan & $4454(8.1)$ & $8149(14.9)$ & \\
\hline Micropolitan & $5098(9.3)$ & $7522(13.8)$ & \\
\hline Non-core & $4423(8.1)$ & $5246(9.6)$ & \\
\hline \multicolumn{3}{|l|}{$\begin{array}{l}\text { Median household income } \\
\text { by ZIP code, \$: }\end{array}$} & \multirow[t]{4}{*}{0.07} \\
\hline$<40000$ & $12269(22.4)$ & $13312(24.3)$ & \\
\hline $40000-100000$ & $39236(71.7)$ & $38824(71.0)$ & \\
\hline$>100000$ & $3186(5.8)$ & $2548(4.7)$ & \\
\hline Mean (SD) Elixhauser comorbidities count & $2.2(1.0)$ & $2.2(1.0)$ & 0.03 \\
\hline \multicolumn{4}{|l|}{ Hospital diagnoses: } \\
\hline Respiratory failure & $9042(16.5)$ & $8770(16.0)$ & 0.01 \\
\hline Shock & $8955(16.4)$ & $8655(15.8)$ & 0.01 \\
\hline Cardiac arrest & $10658(19.5)$ & $10426(19.1)$ & 0.01 \\
\hline \multicolumn{4}{|c|}{ Procedures performed during hospital admission: } \\
\hline Percutaneous coronary intervention & $46212(84.5)$ & $45815(83.8)$ & 0.02 \\
\hline Coronary artery bypass grafting & $3506(6.4)$ & $3352(6.1)$ & 0.01 \\
\hline Thrombolytics & $958(1.8)$ & $1116(2.0)$ & 0.02 \\
\hline Mechanical ventilation & $7981(14.6)$ & $7561(13.8)$ & 0.02 \\
\hline Renal replacement therapy & $590(1.1)$ & $529(1.0)$ & 0.01 \\
\hline Mechanical cardiac support§ & $5868(10.7)$ & $5248(9.6)$ & 0.04 \\
\hline Targeted temperature management & $308(0.6)$ & $344(0.6)$ & 0.01 \\
\hline \multicolumn{3}{|l|}{ Angus organ failure score: } & \multirow[t]{3}{*}{0.03} \\
\hline 0 & $32584(59.6)$ & $33377(61.0)$ & \\
\hline$\geq 1$ & $22107(40.4)$ & $21307(39.0)$ & \\
\hline Billing encounter for palliative care & $9784(17.9)$ & $9308(17.0)$ & 0.02 \\
\hline \multicolumn{4}{|c|}{$\begin{array}{l}\text { *Hospital in top quarter of ICU admission rates for ST elevation myocardial infarction. } \\
\text { tInstrument used for this study, representing additional distance patient would need to travel beyond nearest } \\
\text { hospital to arrive at high ICU use hospital. Median differential distance was } 6.8 \text { miles. } \\
\text { fAbsolute standardized difference of } \geq 0.10 \text { generally indicates that covariates are imbalanced between groups. }{ }^{26} \\
\text { §Percutaneous ventricular assist device or intra-aortic balloon pump. }\end{array}$} \\
\hline
\end{tabular}

We used SAS 9.3 and Stata 14.2 for data management and analyses. The analytic code is included in the supplementary methods. All tests were two sided with a $P$ value less than 0.05 considered significant.

\section{Results}

Between January 2014 and October 2015, 109375 patients with STEMI were admitted to 1727 hospitals (supplementary figure A). Among these patients, $75227(68.8 \%)$ were admitted to an ICU. Patients admitted to an ICU were more likely to be younger, to be male, and to be sicker by the number of organ failures than non-ICU patients, although both had a similar number of Elixhauser comorbidities (table 2). ICU patients were also more likely to receive procedures such as percutaneous coronary intervention, coronary artery bypass graft, or thrombolytics, as well as other procedures such as renal replacement therapy, ${ }^{33}$ mechanical cardiac support, ${ }^{34}$ cardiac arrest, ${ }^{35}$ or targeted temperature management (table 2). ${ }^{35}$ STEMI patients from the south were more likely to be admitted to an ICU than were other patients. Differences were appropriately balanced by the instrument, except for race/ethnicity and urbanicity (table 1). We identified $431(25 \%)$ hospitals as having high ICU use for STEMI, with ICU admission rates of $85 \%$ or greater (fig 1 ). High ICU use hospitals had lower rates of intermediate care use and were more likely to have fewer than 100 hospital beds and a higher proportion of hospital beds that were ICU beds (table 3).

Patients with STEMI who were admitted to an ICU had higher unadjusted 30 day mortality than STEMI patients admitted to non-ICU units $(18.2 \%$ for ICU admission versus $13.8 \%$ for non-ICU admission) (table 4). In a multivariable regression adjusted for characteristics of patients and hospitals, ICU admission for STEMI was associated with an increase in 30 day mortality compared with non-ICU care $(17.0 \%$ for ICU admission versus $16.5 \%$ for non-ICU admission; absolute increase 0.5 (95\% confidence interval 0.3 to 1.0) percentage points).

We estimated that approximately one in 10 patients in this study had borderline ICU needs (that is, received ICU or non-ICU care dependent only on their proximity to a given hospital) (supplementary table B). The population of patients with borderline ICU needs was more likely to be over the age of 85 , have no organ failures, live in the western US, or have a median household income by ZIP code of more than $\$ 100000$ (€77 000; €90 000) (supplementary table C).

In the instrumental variable analysis, ICU admission was associated with lower 30 day mortality compared with non-ICU admission (14.9\% for ICU admission versus $21.0 \%$ for non-ICU admission; $\mathrm{P}=0.04$ ), with an absolute reduction in 30 day mortality of $6.1(-11.9$ to -0.3) percentage points) (table 4).

Subgroup analyses showed results consistent with the main effect. Point estimates were consistent with the main result for subgroups of race/ethnicity and urbanicity. Point estimates favored a benefit to ICU admission across organ failures and age strata; after exclusion of severely ill patients, patients who received a billing encounter for palliative care, patients who did not receive an intervention for STEMI, or patients admitted to hospitals without percutaneous coronary intervention or intermediate care capabilities; and when the association of ICU admission was estimated using a two stage residual inclusion model. A falsification test in which the instrumental variable analysis was repeated for non-STEMI patients showed no mortality benefit associated with ICU admission (absolute increase 1.3 (-0.9 to 3.4) percentage points) (fig 2; supplementary table D, supplementary figure B). 


\begin{tabular}{|c|c|c|}
\hline Characteristics & ICU & Non-ICU \\
\hline Patients & $75227(68.8)$ & $34148(31.2)$ \\
\hline Mean (SD) age, years & $75.6(7.6)$ & $77.1(8.3)$ \\
\hline \multicolumn{3}{|l|}{ Age group, years: } \\
\hline $65-74$ & $38598(51.3)$ & $15388(45.1)$ \\
\hline 75-84 & $24485(32.6)$ & $10505(30.8)$ \\
\hline$\geq 85$ & $12144(16.1)$ & $8255(24.2)$ \\
\hline \multicolumn{3}{|l|}{ Sex: } \\
\hline Male & $45352(60.3)$ & $18692(54.7)$ \\
\hline Female & $29875(39.7)$ & $15456(45.3)$ \\
\hline \multicolumn{3}{|l|}{ Race/ethnicity: } \\
\hline White & $65279(86.8)$ & $29786(87.2)$ \\
\hline Black & $5279(7.0)$ & $2268(6.6)$ \\
\hline Other & $4669(6.2)$ & $2094(6.1)$ \\
\hline \multicolumn{3}{|l|}{ Urbanicity: } \\
\hline Large central metropolitan & $17146(22.8)$ & $8107(23.7)$ \\
\hline Large suburban metropolitan & $17217(22.9)$ & $7759(22.7)$ \\
\hline Medium metropolitan & $16498(21.9)$ & $7756(22.7)$ \\
\hline Small metropolitan & $8514(11.3)$ & $4089(12.0)$ \\
\hline Micropolitan & $8991(12.0)$ & $3629(10.6)$ \\
\hline Non-core & $6861(9.1)$ & $2808(8.2)$ \\
\hline \multicolumn{3}{|l|}{ Median household income by ZIP code, \$: } \\
\hline$<40000$ & $18057(24.0)$ & $7524(22.0)$ \\
\hline $40000-100000$ & $53260(70.8)$ & $24800(72.6)$ \\
\hline$>100000$ & $3910(5.2)$ & $1824(5.3)$ \\
\hline Mean (SD) Elixhauser comorbidities count & $3.0(1.9)$ & $2.9(1.9)$ \\
\hline \multicolumn{3}{|l|}{ Hospital diagnoses: } \\
\hline Respiratory failure & 15001 (19.9) & $2811(8.2)$ \\
\hline Shock & $15413(20.5)$ & $2197(6.4)$ \\
\hline Cardiac arrest & $16758(22.3)$ & $4326(12.7)$ \\
\hline \multicolumn{3}{|l|}{ Procedures performed during hospital admission: } \\
\hline Percutaneous coronary intervention & $65970(87.7)$ & $26057(76.3)$ \\
\hline Coronary artery bypass grafting & $6013(8.0)$ & $845(2.5)$ \\
\hline Thrombolytics & $1555(2.1)$ & $519(1.5)$ \\
\hline Mechanical ventilation & $13767(18.3)$ & $1775(5.2)$ \\
\hline Renal replacement therapy & $993(1.3)$ & $126(0.4)$ \\
\hline Mechanical cardiac support* & $10075(13.4)$ & $1041(3.1)$ \\
\hline Targeted temperature management & $614(0.8)$ & $38(0.1)$ \\
\hline \multicolumn{3}{|l|}{ Angus organ failure score: } \\
\hline 0 & $41742(55.5)$ & $24219(70.9)$ \\
\hline$\geq 1$ & $33485(44.5)$ & $9929(29.1)$ \\
\hline Billing encounter for palliative care & $4136(5.5)$ & $1863(5.5)$ \\
\hline Median (interquartile range) length of index hospital admission, days & $3(2-6)$ & $3(2-4)$ \\
\hline \multicolumn{3}{|l|}{ Discharge destination of index hospital admission: } \\
\hline Home & $52124(69.3)$ & $25604(75.0)$ \\
\hline Rehabilitation or nursing facility & $8567(11.4)$ & $3714(10.9)$ \\
\hline Other & $3789(5.0)$ & $1987(5.8)$ \\
\hline In-hospital mortality & $10747(14.3)$ & $2843(8.3)$ \\
\hline
\end{tabular}

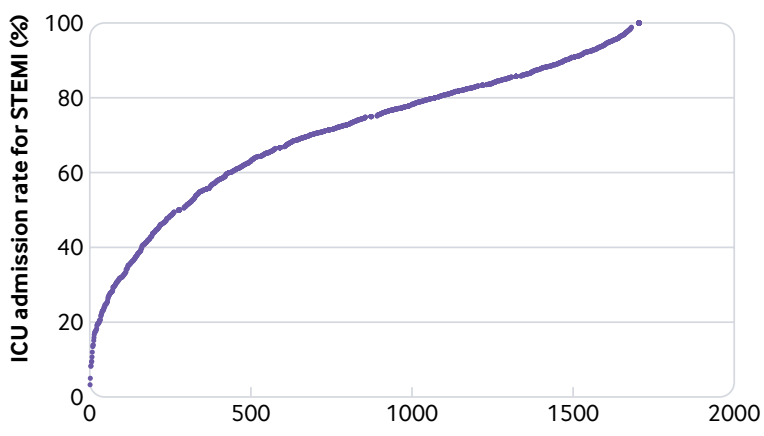

Hospitals ranked by ICU admission rate for STEMI

Fig 1 | Distribution of intensive care unit (ICU) admission rates for ST elevation myocardial infarction (STEMI). Each circle represents an individual hospital, based on its ICU admission rate for STEMI and then ranked by its ICU admission rate for STEMI

\section{Discussion}

Admission to ICU was associated with an absolute survival benefit of 6.1 percentage points at 30 days for STEMI patients with borderline or discretionary ICU needs. This association persisted in several subgroup and falsification analyses. Contrary to the prespecified hypothesis, we found that ICU care may be underused for certain patients with STEMI. This finding has important implications given the rising costs and use of critical care services globally.

\section{Findings in context}

Whether patients with STEMI benefit from ICU care has been uncertain. No randomized trials have evaluated the use of ICU care for STEMI, and guidelines do not 


\begin{tabular}{|c|c|c|}
\hline Characteristics & High ICU use* & Low ICU use* \\
\hline Hospital & $431(25.0)$ & $1296(75.0)$ \\
\hline Mean (SD) ICU admission rate for STEMI, \% & $91.7(4.5)$ & $63.7(17.6)$ \\
\hline Mean (SD) intermediate care admission rate for STEMI, \% & $3.0(4.3)$ & $22.8(20.1)$ \\
\hline Median (SD) hospital STEMI annual case volume & $47(23-77)$ & $51(28-86)$ \\
\hline Median (SD) hospital PCI/CABG annual case volume & $43(21-73)$ & $46(25-81)$ \\
\hline \multicolumn{3}{|l|}{ Hospital ownershipt: } \\
\hline For profit & $94(22.0)$ & $278(21.7)$ \\
\hline Not for profit & $258(60.3)$ & $871(67.9)$ \\
\hline Government & $76(17.8)$ & $133(10.4)$ \\
\hline Medical school affiliated & $209(48.5)$ & $624(48.2)$ \\
\hline \multicolumn{3}{|l|}{ Teaching status: } \\
\hline No residents & $312(72.4)$ & $956(73.8)$ \\
\hline Minor teaching program $(<0.25$ residents $/$ bed $)$ & $67(15.6)$ & $211(16.3)$ \\
\hline Major teaching program ( $>0.25$ residents $/$ bed $)$ & $52(12.1)$ & $129(10.0)$ \\
\hline \multicolumn{3}{|l|}{ Hospital beds: } \\
\hline$<100$ & $57(13.2)$ & $100(7.7)$ \\
\hline 100-199 & $107(24.8)$ & $350(27.0)$ \\
\hline$>199$ & $267(62.0)$ & $846(65.3)$ \\
\hline \multicolumn{3}{|l|}{ Percentage of total beds that are ICU beds: } \\
\hline$<\%$ & $52(12.1)$ & $191(14.7)$ \\
\hline $5-10 \%$ & $117(27.2)$ & $438(33.8)$ \\
\hline$>10 \%$ & $262(60.8)$ & $667(51.5)$ \\
\hline \multicolumn{3}{|l|}{ Medicaid patients served: } \\
\hline$<16 \%$ & $134(31.1)$ & $442(34.1)$ \\
\hline $16-23 \%$ & $139(32.3)$ & $437(33.7)$ \\
\hline$>23 \%$ & $158(36.7)$ & $417(32.2)$ \\
\hline Mean (SD) nursing ratio, FTE per 1000 patient days & $4.2(1.3)$ & $4.2(1.3)$ \\
\hline \multicolumn{3}{|l|}{ Census regions: } \\
\hline North east & $66(15.3)$ & $206(15.9)$ \\
\hline Midwest & $114(26.5)$ & $317(24.5)$ \\
\hline South & $190(44.1)$ & $498(38.4)$ \\
\hline West & $61(14.2)$ & $275(21.2)$ \\
\hline \multicolumn{3}{|c|}{$\begin{array}{l}\text { CABG=coronary artery bypass graft; } \mathrm{FTE}=\text { full time equivalents; } \mathrm{PCl}=\text { percutaneous coronary intervention; } \\
\text { STEMI=ST elevation myocardial infarction. } \\
\text { *High ICU use indicates ICU admission rate for STEMI } \geq 85.2 \% \text {. Low ICU use indicates ICU admission rate for } \\
\text { STEMI <85.2\%. } \\
\text { tOwnership information was missing for } 17 \text { hospitals. }\end{array}$} \\
\hline
\end{tabular}

offer consistent recommendations about whether to admit STEMI patients to an ICU. ${ }^{167}$ As a result, tremendous variation exists in whether ICUs are used for patients with myocardial infarction, both in the US and globally. ${ }^{38}$

This variation is clinically relevant because, despite the decrease in mortality for myocardial infarction over time, ${ }^{10}$ our ability as clinicians to identify patients at high risk of decompensation has not necessarily improved. ${ }^{3637}$ Thus, although inpatient care for STEMI

\begin{tabular}{|c|c|c|}
\hline Model & Absolute 30 day mortality, $\%(95 \% \mathrm{Cl})$ & $P$ value \\
\hline \multicolumn{3}{|c|}{ Unadjusted results } \\
\hline $\mathrm{ICU}$ & 18.2 & - \\
\hline Non-ICU & 13.8 & - \\
\hline \multicolumn{3}{|c|}{ Adjusted model* } \\
\hline $\mathrm{ICU}$ & $17.0(16.7$ to 17.3$)$ & Reference \\
\hline Non-ICU & $16.5(16.1$ to 16.9$)$ & 0.04 \\
\hline \multicolumn{3}{|c|}{ Instrumental variable modelt } \\
\hline ICU & 14.9 (13.1 to 16.7$)$ & Reference \\
\hline Non-ICU & $21.0(17.1$ to 25.0$)$ & 0.04 \\
\hline \multicolumn{3}{|c|}{$\begin{array}{l}\text { *Adjusted for characteristics of patients and hospitals in table } 2 \text { and table } 3 \text {. Standard errors adjusted for } \\
\text { clustering of patients within hospitals. } \\
\text { †Two stage least squares regression of all patients, using differential distance to nearest hospital with high ICU } \\
\text { admission rates as instrumental variable, adjusted for characteristics of patients and hospitals in table } 2 \text { and } \\
\text { table 3. Standard errors adjusted for clustering of patients within hospitals. }\end{array}$} \\
\hline
\end{tabular}

patients may be safer overall, certain populations of patients may continue to be at risk, and efforts to reduce the number of STEMI patients who receive ICU care on average may place these patients at even higher risk in the future.

The results of this study apply specifically to statistically marginal patients and not to those with obvious indications for or against ICU care. ${ }^{28}$ Marginal patients are those who were admitted (or not admitted) to an ICU solely on the basis of their proximity to a given hospital. Clinically, these patients likely have borderline or discretionary ICU needs. In other words, they may be admitted to an ICU in some but not all hospitals because clinicians may disagree about the optimal location of care. Thus, the borderline patients in this study represent a group of patients for whom there is clinical equipoise and unwarranted variation exists in care.

Instrumental variable analyses are unable to identify individual patients who are "marginal" or "borderline." Despite this, we were able to identify population level characteristics associated with these patients. For example, we found that the borderline population was more likely to be older than 85 and have no organ failures. This suggests that the population of patients in this study with those characteristics was particularly vulnerable to local hospital practices and, as a result, was more likely to benefit from ICU admission. Future research can use this profile of borderline patients to design a prospective trial to test whether expanded ICU access improves outcomes for patients with STEMI.

What about ICU care might be beneficial to STEMI patients remains unclear. $^{5}$ Historically, CCUs were developed to monitor for post-infarction complications, such as life threatening ventricular arrhythmias or mechanical sequelae. ${ }^{38}$ The incidence of these complications has been greatly reduced by early reperfusion therapy, ${ }^{39}$ and most STEMI patients receive definitive reperfusion therapy before admission to an ICU or CCU. Thus, neither the existing literature nor our study precisely identifies what about ICU care might be particularly beneficial to these patients.

ICUs in the US are primarily defined by their level of nursing care and by their ability to provide aggressive, lifesaving treatment. STEMI patients with borderline ICU needs, compared with other types of myocardial infarction patients, may benefit from the enhanced nursing care available in ICUs, allowing for earlier detection of complications or decompensation. ${ }^{40}$ The results may also reflect the growing complexity of STEMI patients, who might also present with or develop non-cardiac conditions (for example, pneumonia), for which ICU care may be beneficial. ${ }^{41} 42$ Finally, ICUs may be capable of providing more timely access to particular treatments or may have more effective protocols to ensure the provision of important care (for example, discharge drugs) than non-ICU units. ${ }^{43}$ Thus, the results of this study may have more to do with limitations of non-ICU care rather than the direct benefits of ICU care, suggesting that certain hospitals may be better prepared to care for STEMI patients across different units. ${ }^{44}$ 


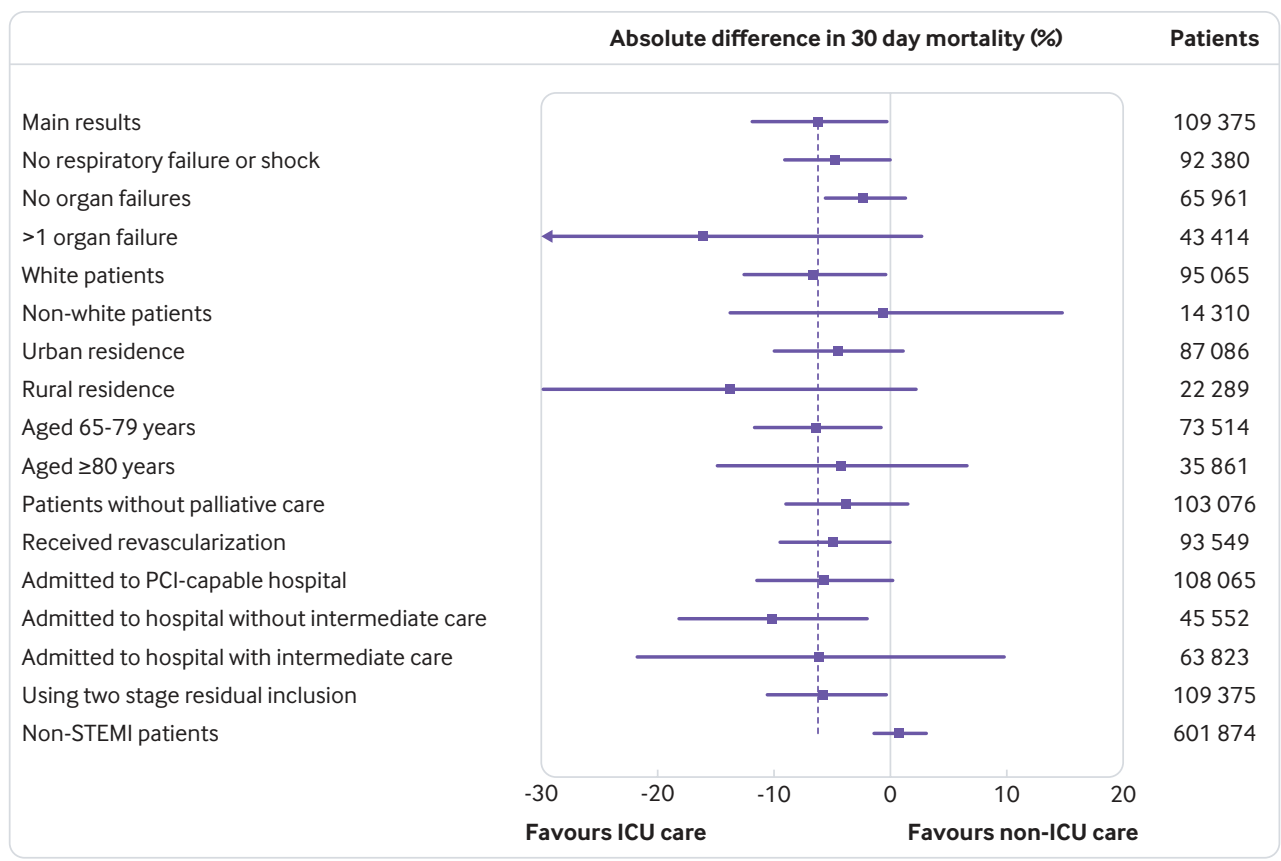

Fig 2 | Subgroup, sensitivity, and falsification analyses. All models used an instrumental variable analysis and adjusted for characteristics of patients and hospitals. Error bars represent $95 \%$ confidence intervals for absolute 30 day mortality differences (intensive care unit (ICU) $v$ non-ICU care). STEMI=ST elevation myocardial infarction

Previous observational studies evaluating the role of ICU care are important to note for two reasons. Firstly, on comparison, the mortality rate in this study may seem unusually high relative to results from recent clinical trials. However, our 30 day mortality rates were consistent with other studies of myocardial infarction among the Medicare population, which is older and at higher risk than the general population..$^{45-47}$ Secondly, most previous studies suggested increased mortality among patients admitted to an ICU, but these studies are at risk for confounding by indication and for estimating average rather than the more clinically relevant marginal treatment effects (that is, the effect on patients who could reasonably be treated in either ICU or non-ICU settings). ${ }^{48-50}$ Our unadjusted and adjusted results also showed increased mortality associated with ICU admission. Other instrumental variable analyses have similarly shown a shift in the effect compared with conventional regression analyses. ${ }^{42} 51$

\section{Strengths and limitations of study}

The quality of an instrumental variable analysis depends on the validity of the instrument. ${ }^{25}$ We showed that differential distance was strongly correlated with ICU admission, showed balance of observed patients' characteristics as a result of the instrument, and did several analyses to evaluate for residual confounding. We used the instrument to look at a separate condition for which ICU care may not be beneficial-non-STEMIand found no association between ICU admission and mortality. ${ }^{32}$

This study should be considered in the context of several limitations. Firstly, we used administrative data. Thus, certain clinically relevant variables such as infarct size, blood pressure, left ventricular ejection fraction, Killip class, ${ }^{52}$ culprit vessel, or time to reperfusion were unavailable. Residual confounding based on these factors cannot be ruled out. However, the excellent balance shown by the instrument suggests that unmeasured differences may be balanced as well. In addition, we did several subgroup and falsification analyses, which showed consistent results. Collectively, these results suggest that the effect of differential distance on the outcome operated through changes in the use of ICU care and not through other potential confounders. Secondly, the study's cohort consisted of US Medicare beneficiaries and may not generalize to STEMI patients younger than 65 or to non-US STEMI patients. Thirdly, this study treated intensive care and coronary care units as the same. In many real world settings, these units are often combined to care for critically ill patients; differences between the two units at some hospitals may affect patient care and should be considered in future work. Similarly, key differences may exist between intermediate and general ward/ telemetry care that were not assessed in this study. Finally, most hospitals in this study were non-teaching hospitals, and whether clinical outcomes for STEMI patients may differ between teaching and non-teaching hospitals remains controversial. ${ }^{53-55}$

\section{Implications and conclusions}

This study has important implications for clinicians and health system leaders. Conventional wisdom in the US suggests that ICU care is generally overused and that efforts must be made to reduce the number of patients receiving ICU care. ${ }^{556}$ However, this study, in combination with others ${ }^{42}{ }^{57}$ indicates instead that ICU care may often be misdirected, with some patients 
experiencing underuse while others experience overuse.

ICU admission for STEMI patients with borderline or discretionary ICU needs was associated with improved survival at 30 days. Methods to identify STEMI patients who might benefit from ICU care are needed and should be followed by randomized trials to test the effect of expanded access to ICU and the mechanisms that result in benefit from ICU care.

\section{AUTHOR AFFILIATIONS}

${ }^{1}$ Division of Pulmonary and Critical Care Medicine, Department of Internal Medicine, University of Michigan, Ann Arbor, MI, USA

${ }^{2}$ Institute for Healthcare Policy and Innovation, University of Michigan, Ann Arbor, MI, USA

${ }^{3}$ Center for Bioethics and Social Sciences in Medicine, University of Michigan, Ann Arbor, MI, USA

${ }^{4}$ VA Center for Clinical Management Research, Ann Arbor, MI, USA

${ }^{5}$ Center for Health Outcomes and Policy, University of Michigan, Ann Arbor, MI, USA

${ }^{6}$ Cardiac Intensive Care Unit, Inova Heart and Vascular Institute, Inova Fairfax Medical Center, Falls Church, VA, USA

${ }^{7}$ Cardiovascular Critical Care Research, Inova Heart and Vascular Institute, Inova Fairfax Medical Center, Falls Church, VA, USA

${ }^{8}$ Richard and Susan Smith Center for Outcomes Research in Cardiology, Beth Israel Deaconess Medical Center, Boston, MA, USA

${ }^{9}$ Department of Medicine, Harvard Medical School, Boston, MA, USA

${ }^{10}$ Division of Cardiovascular Medicine, Department of Internal Medicine, University of Michigan, Ann Arbor, MI, USA

Contributors: TSV and BKN were responsible for study concept and design. TSV obtained funding. TSV and CRC acquired the data, and al authors were involved in analysis and interpretation of data. TSV and BKN drafted the manuscript, and all authors revised it critically for important intellectual content. The corresponding author attests that all listed authors meet authorship criteria and that no others meeting the criteria have been omitted. TSV is the guarantor.

Funding: This work was supported by NIH K23 HL140165 (TSV), K12 HL138039 (TII), and R01 HL137816 (CRC). The funding organizations had no role in the design and conduct of the study; in the collection, analysis, and interpretation of the data; or in the preparation, review, or approval of the manuscript.

Competing interests: All authors have completed the ICMIE uniform disclosure form at www.icmje.org/coi_disclosure.pdf (available on request from the corresponding author) and declare: no support from any organization for the submitted work other than that described above; no financial relationships with any organizations that might have an interest in the submitted work in the previous three years; and no other relationships or activities that could appear to have influenced the submitted work.

Ethical approval: The Institutional Review Board for the University of Michigan approved the study and provided a waiver of consent (HUM00053488)

Data sharing: The statistical code for the analyses is included in the supplementary materials. Additional code can be obtained from the corresponding author on request. Medicare data are not publicly available but can be obtained through the Center for Medicare and Medicaid Services.

Transparency: The lead author affirms that the manuscript is an honest, accurate, and transparent account of the study being reported; that no important aspects of the study have been omitted; and that any discrepancies from the study as planned (and, if relevant, registered) have been explained.

Disclaimer: This manuscript does not necessarily represent the views of the US Government or the Department of Veterans Affairs.

This is an Open Access article distributed in accordance with the Creative Commons Attribution Non Commercial (CC BY-NC 4.0) license, which permits others to distribute, remix, adapt, build upon this work non-commercially, and license their derivative works on different terms, provided the original work is properly cited and the use is noncommercial. See: http://creativecommons.org/licenses/by-nc/4.0/.

1 O'Gara PT, Kushner FG, Ascheim DD, et al, American College of Cardiology Foundation/American Heart Association Task Force on
Practice Guidelines. 2013 ACCF/AHA guideline for the management of ST-elevation myocardial infarction: a report of the American College of Cardiology Foundation/American Heart Association Task Force on Practice Guidelines. Circulation 2013;127:e362-425.

2 Reed GW, Rossi JE, Cannon CP, et al. Acute myocardial infarction Lancet 2017:389:197-210 doi:10.1016/S01406736(16)30677-8

3 Chen R, Strait KM, Dharmarajan K. Hospital variation in admission to intensive care units for patients with acute myocardial infarction. Am Heart J 2015;170:1161-9. doi:10.1016/j.ahj.2015.09.003

4 Barrett ML, Smith MW, Elixhauser A, Honigman LS, Pines JM Utilization of Intensive Care Services, 2011: Statistical Brief \#185. Statistical Briefs 2006;15:1-14

5 Katz JN. Who Belongs in the Cardiac Intensive Care Unit?JAMA Cardiol 2017;2:45-6. doi:10.1001/jamacardio.2016.3881

6 Ibanez B, James S, Agewall S, et al, ESC Scientific Document Group. 2017 ESC Guidelines for the management of acute myocardial infarction in patients presenting with ST-segment elevation: The Task Force for the management of acute myocardial infarction in patients presenting with ST-segment elevation of the European Society of Cardiology (ESC). Eur Heart J 2018;39:119-77. doi:10.1093/ eurheartj/ehx393

7 Antman EM, Anbe DT, Armstrong PW, et al. ACC/AHA guidelines for the management of patients with ST-elevation myocardial infarction; A report of the American College of Cardiology/American Heart Association Task Force on Practice Guidelines (Committee to Revise the 1999 Guidelines for the Management of patients with acute myocardial infarction). J Am Coll Cardiol 2004;44:E1-211. doi:10.1016/j.jacc.2004.07.014

8 Puymirat E, Simon T, Cayla G, et al, USIK, USIC 2000, and FAST-MI investigators. Acute Myocardial Infarction: Changes in Patient Characteristics, Management, and 6-Month Outcomes Over a Period of 20 Years in the FAST-MI Program (French Registry of Acute ST-Elevation or Non-ST-Elevation Myocardial Infarction) 1995 to 2015. Circulation 2017;136:1908-19. doi:10.1161/ CIRCULATIONAHA.117.030798

9 Grobbee DE, Hoes AW. Confounding and indication for treatment in evaluation of drug treatment for hypertension. BMJ 1997;315:1151 4. doi:10.1136/bmj.315.7116.1151

10 Yeh RW, Sidney S, Chandra M, Sorel M, Selby JV, Go AS. Population trends in the incidence and outcomes of acute myocardial infarction. N Engl I Med 2010;362:2155-65. doi:10.1056/NEJMoa0908610

11 Research Data Assistance Center. MedPAR. https://www.resdac.org/ cms-data/files/medpar.

12 American Hospital Association. AHA Annual Survey Database. http:// www.ahadata.com/aha-annual-survey-database-asdb/.

13 Centers for Medicare \& Medicaid Services. Cost Reports. https:// www.cms.gov/Research-Statistics-Data-and-Systems/DownloadablePublic-Use-Files/Cost-Reports/.

14 Centers for Medicare \& Medicaid Services, Department of Health and Human Services. Provider Reimbursement Manual - Part 1 Chapter 22, Determination of Cost of Services to Beneficiaries. 2017. https://www.cms.gov/Regulations-and-Guidance/Guidance/ Transmittals/2017Downloads/R475PR1.pdf.

15 Weissman GE, Hubbard RA, Kohn R, et al. Validation of an Administrative Definition of ICU Admission Using Revenue Center Codes. Crit Care Med 2017;45:e758-62. doi:10.1097/ CCM.0000000000002374

16 Sjoding MW, Valley TS, Prescott HC, Wunsch H, Iwashyna TJ, Cooke CR. Rising Billing for Intermediate Intensive Care among Hospitalized Medicare Beneficiaries between 1996 and 2010. Am J Respir Crit Care Med 2016;193:163-70. doi:10.1164/rccm.201506-12520C

17 Elixhauser A, Steiner C, Harris DR, Coffey RM. Comorbidity measures for use with administrative data. Med Care 1998;36:8-27. doi:10.1097/00005650-199801000-00004

18 Angus DC, Linde-Zwirble WT, Lidicker J, Clermont G, Carcillo J, Pinsky MR. Epidemiology of severe sepsis in the United States: analysis of incidence, outcome, and associated costs of care. Crit Care Med 2001;29:1303-10. doi:10.1097/00003246-20010700000002

19 Wunsch H, Kramer A, Gershengorn HB. Validation of Intensive Care and Mechanical Ventilation Codes in Medicare Data. Crit Care Med 2017:45:e711-4. doi:10.1097/CCM.0000000000002316

20 Agarwal S, Garg A, Parashar A, Jaber WA, Menon V. Outcomes and resource utilization in ST-elevation myocardial infarction in the United States: evidence for socioeconomic disparities. J Am Heart Assoc 2014:3:e001057. doi:10.1161/JAHA.114.001057

21 Hlatky MA, Boothroyd DB, Reitz BA, Shilane DA, Baker LC, Go AS. Adoption and effectiveness of internal mammary artery grafting in coronary artery bypass surgery among Medicare beneficiaries. / Am Coll Cardiol 2014;63:33-9. doi:10.1016/j.jacc.2013.08.1632

22 Ingram DD, Franco SJ. 2013 NCHS Urban-Rural Classification Scheme for Counties. Vital Health Stat 2 2014:(166):1-73.

23 Wooldridge JM. Score diagnostics for linear models estimated by two stage least squares. In: Maddala GS, Phillips PCB, Srinivasan TN, eds. 
Advances in Econometrics and Quantitative Economics: Essays in Honor of Professor C R Rao. Blackwell, 1995: 66-87.

24 McClellan M, McNeil BJ, Newhouse JP. Does more intensive treatment of acute myocardial infarction in the elderly reduce mortality? Analysis using instrumental variables. JAMA 1994;272:859-66. doi:10.1001/jama.1994.03520110039026

25 Wooldridge JM. Econometric Analysis of Cross Section and Panel Data. MIT Press, 2010: 1096.

26 Austin PC. Balance diagnostics for comparing the distribution of baseline covariates between treatment groups in propensity-score matched samples. Stat Med 2009;28:3083-107. doi:10.1002/ sim. 3697

27 Garabedian LF, Chu P, Toh S, Zaslavsky AM, Soumerai SB. Potential bias of instrumental variable analyses for observational comparative effectiveness research. Ann Intern Med 2014;161:131-8. doi:10.7326/M13-1887

28 Harris KM, Remler DK. Who is the marginal patient? Understanding instrumental variables estimates of treatment effects. Health Serv Res 1998;33:1337-60.

29 Angrist JD, Pischke JS. Mostly harmless econometrics: an empiricist's companion. Princeton University Press, 2008: 290. doi:10.2307/j. ctvcm4j72.

30 Hua M, Li G, Clancy C, Morrison RS, Wunsch H. Validation of the V66.7 Code for Palliative Care Consultation in a Single Academic Medical Center. J Palliat Med 2017;20:372-7. doi:10.1089/ jpm.2016.0363

31 Terza JV. Two-Stage Residual Inclusion Estimation in Health Services Research and Health Economics. Health Serv Res 2018;53:1890-9. doi:10.1111/1475-6773.12714

32 Fanaroff AC, Peterson ED, Chen AY, et al. Intensive Care Unit Utilization and Mortality Among Medicare Patients Hospitalized With Non-ST-Segment Elevation Myocardial Infarction. JAMA Cardiol 2017:2:36-44 doi:10.1001/jamacardio.2016.3855

33 Vlasschaert ME, Bejaimal SA, Hackam DG, et al. Validity of administrative database coding for kidney disease: a systematic review. Am J Kidney Dis 2011;57:29-43. doi:10.1053/j. ajkd.2010.08.031

34 Khera R, Cram P, Lu X, et al. Trends in the use of percutaneous ventricular assist devices: analysis of national inpatient sample data, 2007 through 2012. JAMA Intern Med 2015;175:941-50. doi:10.1001/jamainternmed.2014.7856

35 Kim LK, Looser P, Swaminathan RV, et al. Sex-Based Disparities in Incidence, Treatment, and Outcomes of Cardiac Arrest in the United States, 2003-2012. J Am Heart Assoc 2016; 5:e003704. doi:10.1161/JAHA.116.003704

36 Valley TS, Admon AJ, Zahuranec DB, Garland A, Fagerlin A, Iwashyna TJ. Estimating ICU Benefit: A Randomized Study of Physicians. Crit Care Med 2019;47:62-8. doi:10.1097/CCM.0000000000003473

37 Martinoni A, De Servi S, Politi A, et al. Defining high-risk patients with ST-segment elevation acute myocardial infarction undergoing primary percutaneous coronary intervention: a comparison among different scoring systems and clinical definitions. Int J Cardiol 2012;157:20711. doi:10.1016/j.ijcard.2010.12.007

38 Katz JN, Minder M, Olenchock B, et al. The Genesis, Maturation, and Future of Critical Care Cardiology. I Am Coll Cardiol 2016;68:67-79. doi:10.1016/i.jacc.2016.04.036

39 Puerto E, Viana-Tejedor A, Martínez-Sellés M, et al. Temporal Trends in Mechanical Complications of Acute Myocardial Infarction in the Elderly. J Am Coll Cardiol 2018;72:959-66. doi:10.1016/j. jacc.2018.06.031

40 Needleman J, Buerhaus P, Pankratz VS, Leibson CL, Stevens SR, Harris M. Nurse staffing and inpatient hospital mortality. N Engl J Med 2011:364:1037-45. doi:10.1056/NEJMsa1001025

41 Sinha SS, Sjoding MW, Sukul D, et al. Changes in Primary Noncardiac Diagnoses Over Time Among Elderly Cardiac Intensive Care Unit Patients in the United States. Circ Cardiovasc Qual Outcomes 2017;10:e003616. doi:10.1161/ CIRCOUTCOMES.117.003616
42 Valley TS, Sjoding MW, Ryan AM, Iwashyna TJ, Cooke CR. Association of Intensive Care Unit Admission With Mortality Among Older Patients With Pneumonia. JAMA 2015;314:1272-9. doi:10.1001/ jama.2015.11068

43 Sevransky JE, Checkley W, Herrera P, et al, United States Critical Illness and Injury Trials Group-Critical Illness Outcomes Study Investigators. Protocols and Hospital Mortality in Critically III Patients: The United States Critical Illness and Injury Trials Group Critical Illness Outcomes Study. Crit Care Med 2015;43:2076-84. doi:10.1097/ CCM.0000000000001157

44 Valley TS, Sjoding MW, Goldberger ZD, Cooke CR. ICU Use and Quality of Care for Patients With Myocardial Infarction and Heart Failure. Chest 2016;150:524-32. doi:10.1016/i.chest.2016.05.034

45 Khera R, Dharmarajan K, Wang Y, et al. Association of the Hospital Readmissions Reduction Program With Mortality During and After Hospitalization for Acute Myocardial Infarction, Heart Failure, and Pneumonia. JAMA Netw Open 2018;1:e182777. doi:10.1001/ jamanetworkopen.2018.2777

46 Jena AB, Olenski A, Blumenthal DM, Yeh RW, Goldman DP, Romley J. Acute Myocardial Infarction Mortality During Dates of National Interventional Cardiology Meetings. J Am Heart Assoc 2018;7:e008230. doi:10.1161/JAHA.117.008230

47 Glickman SW, Greiner MA, Lin L, et al. Assessment of tempora trends in mortality with implementation of a statewide STsegment elevation myocardial infarction (STEMI) regionalization program. Ann Emerg Med 2012;59:243-252.e1. doi:10.1016/j. annemergmed.2011.07.030

48 Cairns JA, Singer J, Gent M, et al. One year mortality outcomes of all coronary and intensive care unit patients with acute myocardial infarction, unstable angina or other chest pain in Hamilton, Ontario, a city of 375,000 people. Can J Cardiol 1989;5:239-46.

49 Karlson BW, Herlitz J, Wiklund O, Pettersson P, Hallgren P, Hjalmarson A. Characteristics and prognosis of patients with acute myocardial infarction in relation to whether they were treated in the coronary care unit or in another ward. Cardiology 1992;81:134-44. doi:10.1159/000175788

50 Parhar K, Millar V, Zochios V, et al. Clinical outcomes of patients undergoing primary percutaneous coronary intervention for acute myocardial infarction requiring the intensive care unit. / Intensive Care 2018;6:5. doi:10.1186/s40560-018-0275-y

51 Stukel TA, Fisher ES, Wennberg DE, Alter DA, Gottlieb DJ, Vermeulen M). Analysis of observational studies in the presence of treatment selection bias: effects of invasive cardiac management on AM survival using propensity score and instrumental variable methods. JAMA 2007;297:278-85. doi:10.1001/jama.297.3.278

52 Killip T3rd, Kimball JT. Treatment of myocardial infarction in a coronary care unit. A two year experience with 250 patients. Am J Cardiol 1967;20:457-64. doi:10.1016/0002-9149(67)90023-9

53 Shahian DM, Nordberg P, Meyer GS, et al. Contemporary performance of U.S. teaching and nonteaching hospitals. Acad Med 2012;87:701 8. doi:10.1097/ACM.0b013e318253676a

54 O'Brien E, Subherwal S, Roe MT, et al. Do patients treated at academic hospitals have better longitudinal outcomes after admission for non-ST-elevation myocardial infarction?Am Heart / 2014;167:762-9. doi:10.1016/j.ahj.2014.01.009

55 Burke LG, Frakt AB, Khullar D, Orav EJ, Jha AK. Association Between Teaching Status and Mortality in US Hospitals. JAMA 2017;317:2105-13. doi:10.1001/jama.2017.5702

56 Gooch RA, Kahn JM. ICU bed supply, utilization, and health care spending: an example of demand elasticity. JAMA 2014:311:567-8. doi:10.1001/jama.2013.283800

57 Valley TS, Sjoding MW, Ryan AM, Iwashyna TJ, Cooke CR. Intensive Care Unit Admission and Survival among Older Patients with Chronic Obstructive Pulmonary Disease, Heart Failure, or Myocardial Infarction. Ann Am Thorac Soc 2017;14:943-51. doi:10.1513/ AnnalsATS.201611-8470C

\section{Supplementary materials}

